\title{
Camera-based Visual Rope Inspection
}

\author{
Gregor Novak* \\ Institute for Mechanical Handling and Logistics, University of Stuttgart, Germany \\ * Correspondence: gregor.novak@ift.uni-stuttgart.de
}

Received 1 October 2020; Accepted 5 October 2020; Available online 7 December 2020

(C) 2020 by G. Novak. This is an open access article distributed under the Creative Commons Attribution License (CC-BY 4.O), which permits unrestricted use, distribution, and reproduction in any medium, provided the original work is properly cited.

\begin{abstract}
The manual visual inspection of ropes, both wire and fibre ropes, is still the preferred method of choice for the inspection of suspension means and for safety assessment. As the ropes are usually of a longer length of several hundred metres, manual visual inspection can lead to undetected defects due to inspector fatigue. On the other hand, the inspector only sees the surface facing him and there is no recorded data of the inspection that can be used for clarification in case of a rope breakage. Due to these points, it is advantageous to perform an automated camera-based inspection where several cameras are arranged around the rope. Especially with high modular fibre ropes, which are used in more and more fields of application, visual inspection is a decisive point in the evaluation of operational safety. IFT is currently conducting and has conducted research projects in this field of work.
\end{abstract}

KEYWORDS visual inspection, fibre rope, wire rope, inspection, rope lifetime

\section{Introduction}

Ropes, wire and fibre ropes, that are used in running applications like elevators, cranes etc. have a limited lifetime. Therefore, the ropes have to be monitored in certain intervals according to their load regime and the valid rules and standards.

For wire ropes several methods are available like magneto-inductive rope testing [1], (automated) visual inspection or special methods like X-Ray, ultrasonic or the use of acoustic sensors. The rules and standards that can be applied for the monitoring and inspection of wire ropes are much elaborated.

For fibre ropes on the other hand a single guideline exists that deals with the inspection of fibre ropes [2]. The methods of evaluating and monitoring fibre ropes are less advanced and elaborated compared to wire ropes. The most used method is the rather simple visual inspection by a person $[3,4]$. Several other methods were investigated over the last years like implementing coated fibres to use the method of MRT [5] or the usage of ultrasonic [6].

At IFT a system for the automated visual inspection and monitoring of fibre ropes is currently developed called Fibrespect, based on a system that originates in ropeway and 
mining applications [7]. This paper deals with the current developments of IFT in this field and gives a brief outlook in coming developments.

\section{Overview on methods for non-destructive testing of fibre ropes}

\subsection{Magneto inductive rope testing (MRT) on fibre ropes}

The advantage of wire ropes is their rather simple way to inspect them by using the magneto inductive rope testing method where the wire rope is magnetized, usually with permanent magnets. In case of a wire break a stray field exists. Because of the change of the magnetic field, this can be measured and detected by a coil or hall sensors [8].

Fibre ropes of course cannot be magnetized but it has been shown that coated fibres can be implemented in the rope assembly [5]. These coated fibres can be magnetized like in a standard MRT for wire ropes. If these fibres break, a similar signal can be obtained and further evaluated. The challenge with this method, where only a portion of the fibres are coated is the right design of the whole tension member to have a break of these fibres before the strength members are breaking extensively. In addition, it is a rather limiting solution for the operators since this method can only be used with ropes from a specific manufacturer.

\subsection{Ultrasonic inspection of fibre ropes}

The usage of ultrasonic inspection for fibre ropes can help to identify loss of material within the rope, which leads to a reduction in strength. It is a contact-free technology, like the other mentioned inspection methods, and could be used on different ropes of different manufacturers. To fully use the system, it needs to be known how the reduction of material is related to the loss of strength and to the lifetime of the rope.

\subsection{Visual inspection of fibre ropes}

The visual inspection of ropes can be divided into the manual inspection and the automated, software-assisted, inspection.

\section{Manual visual inspection}

The manual visual inspection of ropes is a long time used method that is mandatory in a series of guidelines and standards for wire ropes as well as for fibre ropes. The advantage of the manual visual inspection is the simplicity with which it can be done. No further tools for assistance are needed and it can be done in more or less every environment. The disadvantages are mainly the human factor and the fact that no (continuous) recordings are available afterwards. The human factor is mostly based on the fact that if the rope is passing the inspector with a rather slow speed, so that he can see and recognizes something, after a few dozen meters of rope he will see a straight line. Also, a disadvantage is the missing continuous recording of the inspection. For the above mentioned MRT and Ultrasonic inspection software-based recording can be done and in the event of an accident be used for 
an analysis. This cannot be done with a manual visual inspection and it has to be relied on the memory and testimony of the inspector.

\section{Automated visual inspection}

An automated visual inspection can help to overcome the above-mentioned disadvantages of a manual visual inspection and can give further advantages and additional values.

The main advantage is the relief of the inspector of an exhaustive work itself and sometimes from an exhaustive work environment. The measurement can be done with a normal speed, which reduces the downtime of the machine. The inspector can use the software to evaluate the rope and make a decision in a short period.

The additional values can include a continuous measurement of several different rope parameters like the rope diameter or the lay length. These parameters will be shown and discussed in more detail in Chapter 4 of this paper.

This kind of monitoring is not only interesting for fibre ropes that are being used in cranes for example but also for the production of such ropes. An automated visual inspection system could be installed at the end of the rope-making machine right in front of the storage drum. The rope is running through the device and defects could be located. This would help the quality management overall and specifically in cases of complaints.

\subsection{Monitoring of rope parameters by using machine sensors}

An alternative for monitoring the condition of fibre ropes is the measurement of rope parameters, especially the rope elongation. This approach can rather simply be used in applications where rope drums are used by utilizing the rotary encoder. For applications where no drum is used, e.g. elevators, a distance measurement on or to the counter weight could be used.

Test accompanying measurements during research projects and student project at IFT showed promising first results. In a greater research project, which focused on the lifetime of high modulus fibre rope in S/R-machines. For this, tests were done on an actual S/Rmachine, which was built up in a previous research project. The rope lengthening was measured with the fully loaded car in the upper position (Figure 1). After an initial lengthening, a rather stable evolution of the elongation took place with an accelerated rise at the end of the lifetime of the rope.

With such an implemented monitoring, a final emergency shut down could be done for cases where the above mentioned, or other, monitoring systems did not evaluate exactly the end of the rope lifetime.

\subsection{Multi-dimensional evaluation approach}

A possible approach to ensure a safe use of fibre ropes in rope drives the discard criterias should be used in combination like it is done in ISO 4309 for wire ropes [9]. For wire ropes a series of discard criteria exist, like the reduction of the diameter and of course 


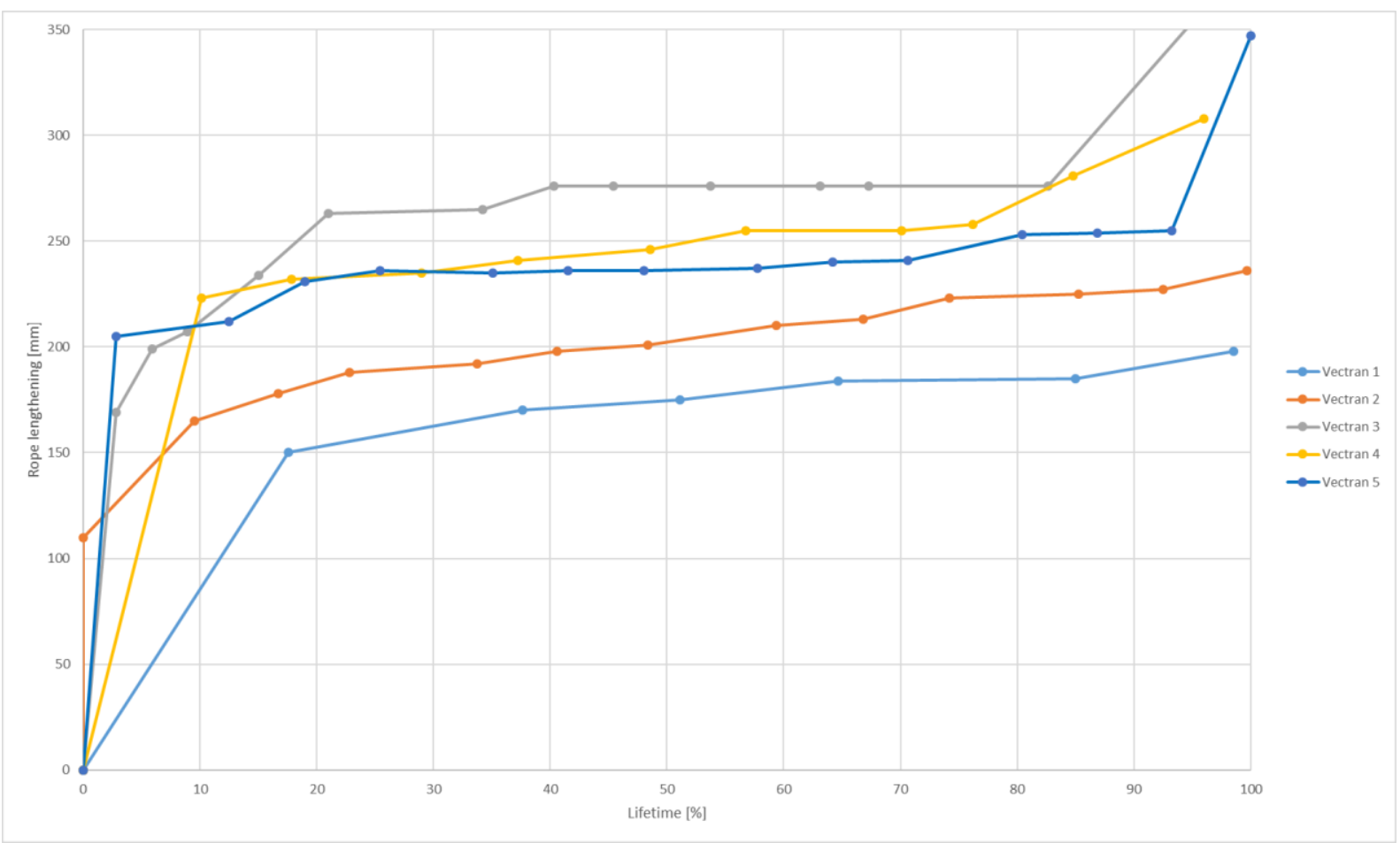

Figure 1: Rope lengthening of several braided Vectran ropes during practical tests on a S/R-machine

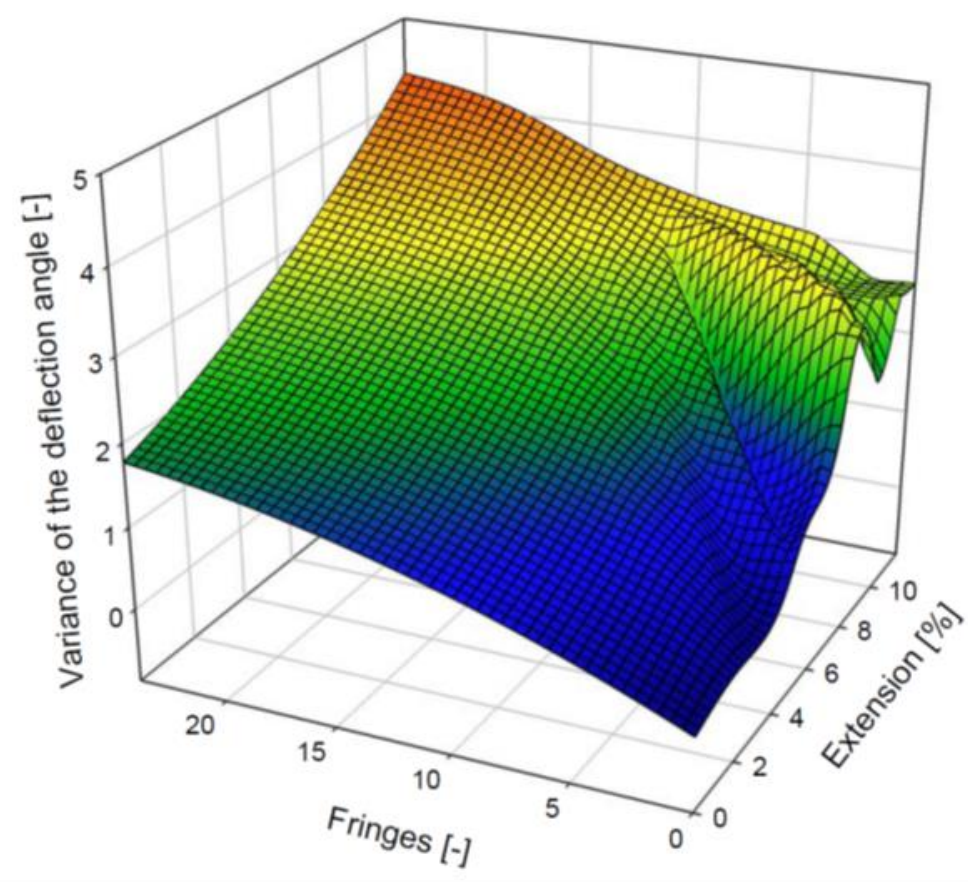

Figure 2: Example for the multidimensional evaluation of different discard criteria

the number of wire breaks on a defined length, which all can be used stand-alone. But for a full picture of the state of the wire rope it is useful to combine these criteria to have a safe use of the rope.

For fibre ropes, it is of more importance than with wire ropes to combine several discard criteria to cover every aspect of the failure mechanisms [10]. The evaluation of this combination of different discard criteria could be done with Fuzzy Logic. The Fuzzy Logic is 
based on the usage of "If" - "Then" clauses where the different discard criterias are compared using logical connectives like "And”. In Figure 2 an example is given where a normal operation of the rope can be continued in the blue and green areas and the discard is reached in the yellow marked area. The logic behind this would be:

IF Fringes=15 AND Extension=8.1 AND Variance of deflection angle=3.2 THEN Discard the rope

\section{Research projects and used test setups}

In several research projects and student projects at IFT the automated visual inspection with the Winspect ${ }^{\circledR}$-system was researched. For these investigations one or several standard cameras of the Winspect ${ }^{\circledR}$-system were used in combination with the standard illumination and the standard recording software. For this paper we will focus on two projects, one ZIM-funded research project [11] and one student project [12] that ran within a bigger research project that was financed by the state of Baden-Württemberg, Germany.

The research project was a ZIM-funded project where tests were done on an S/R-machine at IFT (Figure 3) with several different rope constructions (braided, Wire Rope Construction/laid with and without cover) made of different materials (Dyneema,

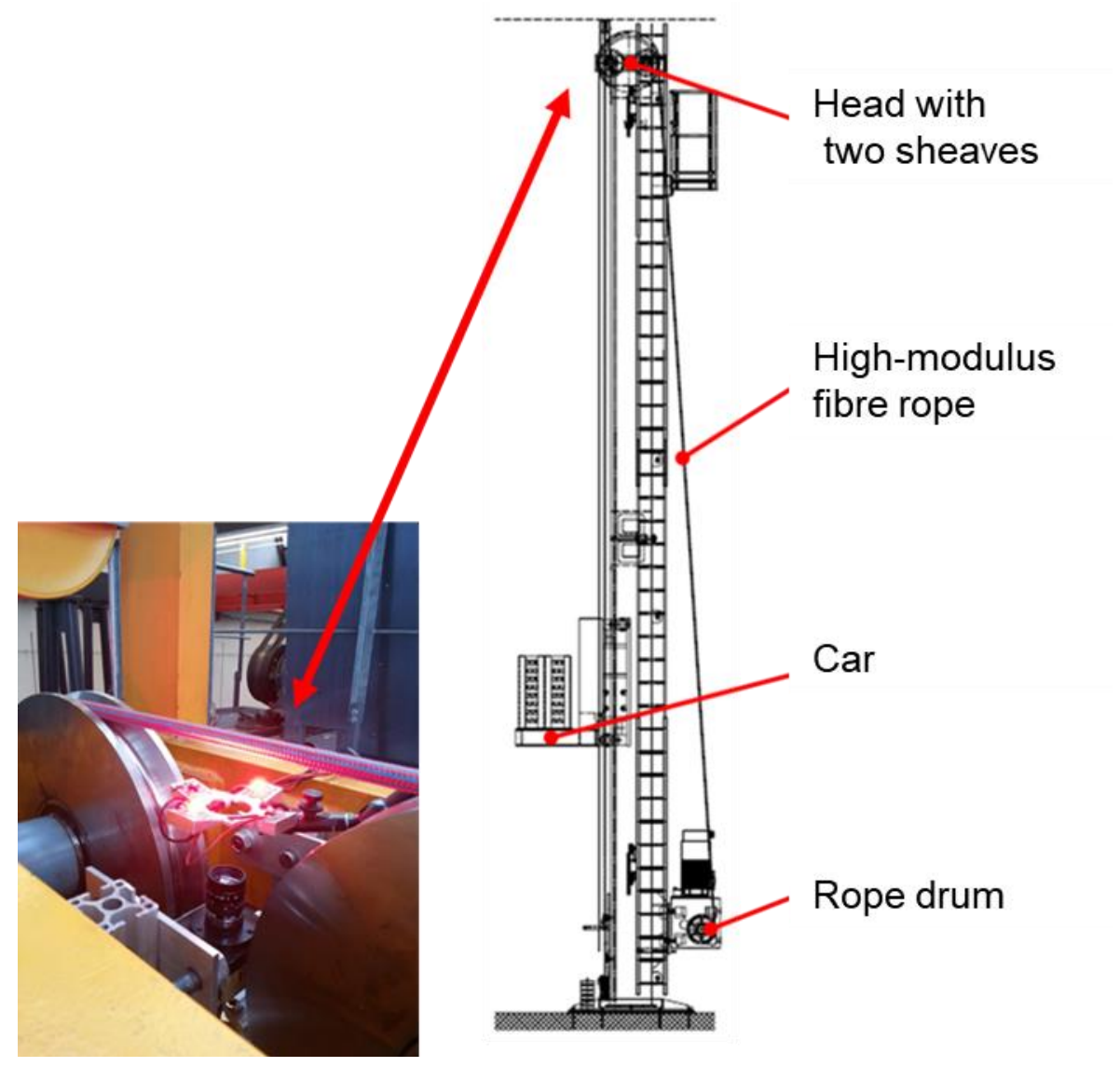

Figure 3: S/R-machine at IFT with camera-setup 
Technora, Vectran). The rope was loaded with a constant force due to the weight in the car and was continuously driven up and down. In certain intervals (in most cases once per day) the machine was stopped and a measurement with the Winspect ${ }^{\circledR}$-camera was done. Afterwards the machine was restarted, the tests were usually run until the rope broke. Sometimes it was stopped prior to this when it was observed that the rope was just before the point of break.

In the student project, ropes that were tested in bending tests were investigated. In a first step, the rope samples were tested until break and in a second step bending tests were performed to certain intervals $(20 \%, 40 \%$, etc.) and the rope samples were taken from the machine to be investigated later. With this approach, it was possible to have the same conditions during the recordings.

The recordings were evaluated by using the standard Winspect software as well as by using specifically programmed software in combination with other software like Microsoft Excel.

\section{Results}

During the tests, several recordings were made as described above. With these recordings, the evaluations for the diameter reduction and the lay length were done but also new approaches were investigated.

In Figure 4 an example for the diameter measurement can be seen and in Figure 5 a corresponding diagram of such an evaluation. In this example, the diameter was not directly measured but the major ellipse axis of the rope. Because of this, the line is rising in the diagram. At $80 \%$, the line is rising in a steeper way, which could be used as a point of discard.

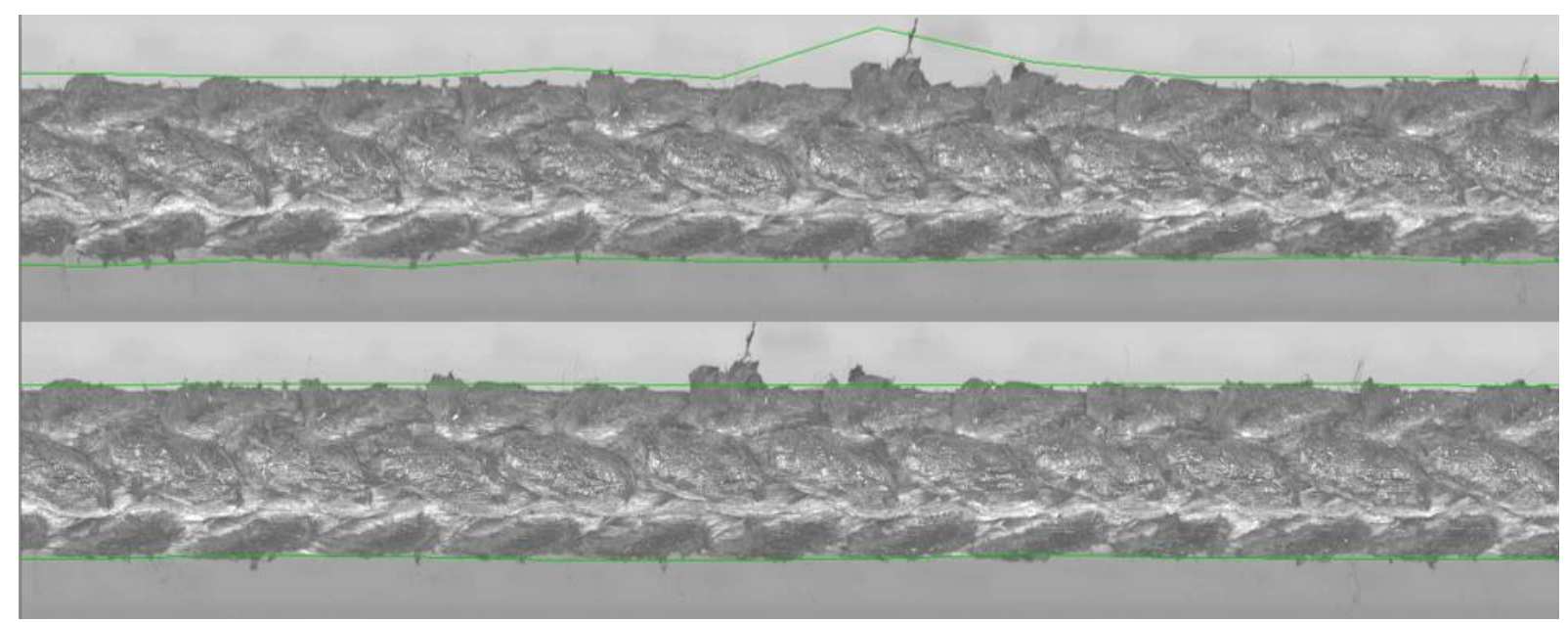

Figure 4: Measurement of rope diameter 


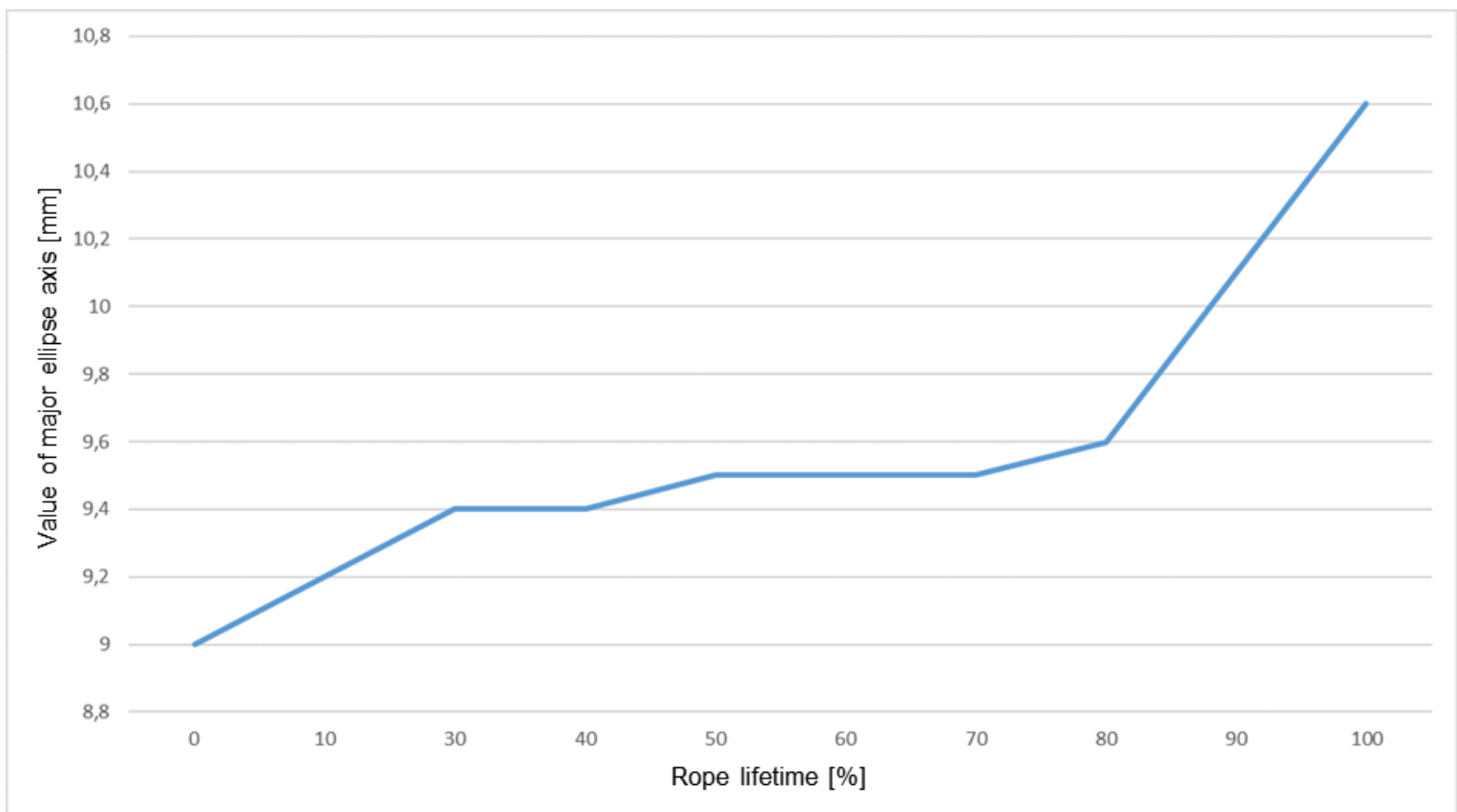

Figure 5: Diagram of rope diameter (major ellipse axis) measurement

In Figure 6 the development of the colour intensity over the lifetime can be seen of an open braid. In Figure 7 the corresponding diagram can be seen where the increase of the values over the lifetime can be seen as a function of the RGB-value. After a rather steep rise at the beginning, the rate is slowing down to the end of the lifetime. For example, the turning point of the line (in this example at about 50\%) could be used as a discard point.

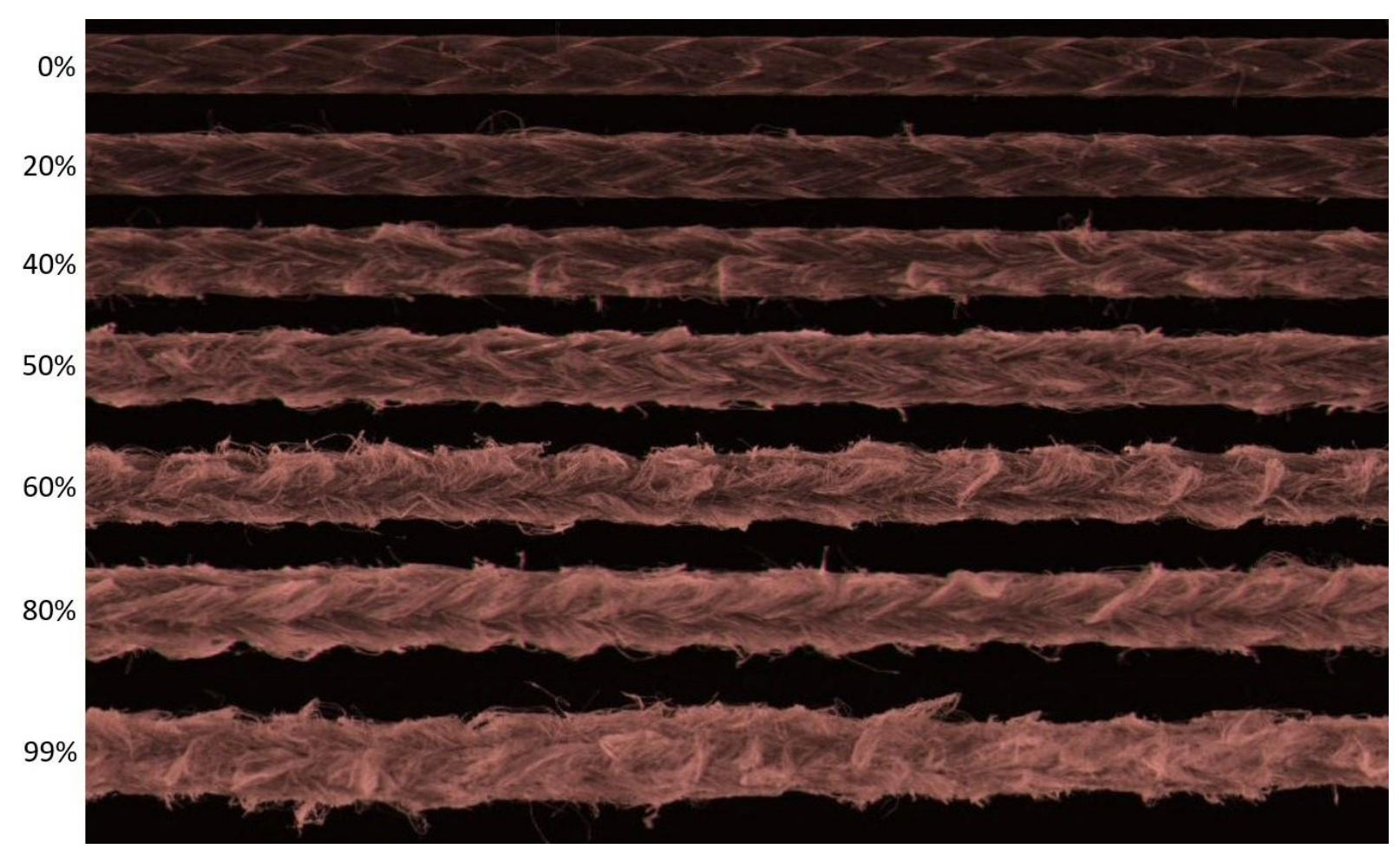

Figure 6: Change of colour intensity over the lifetime 


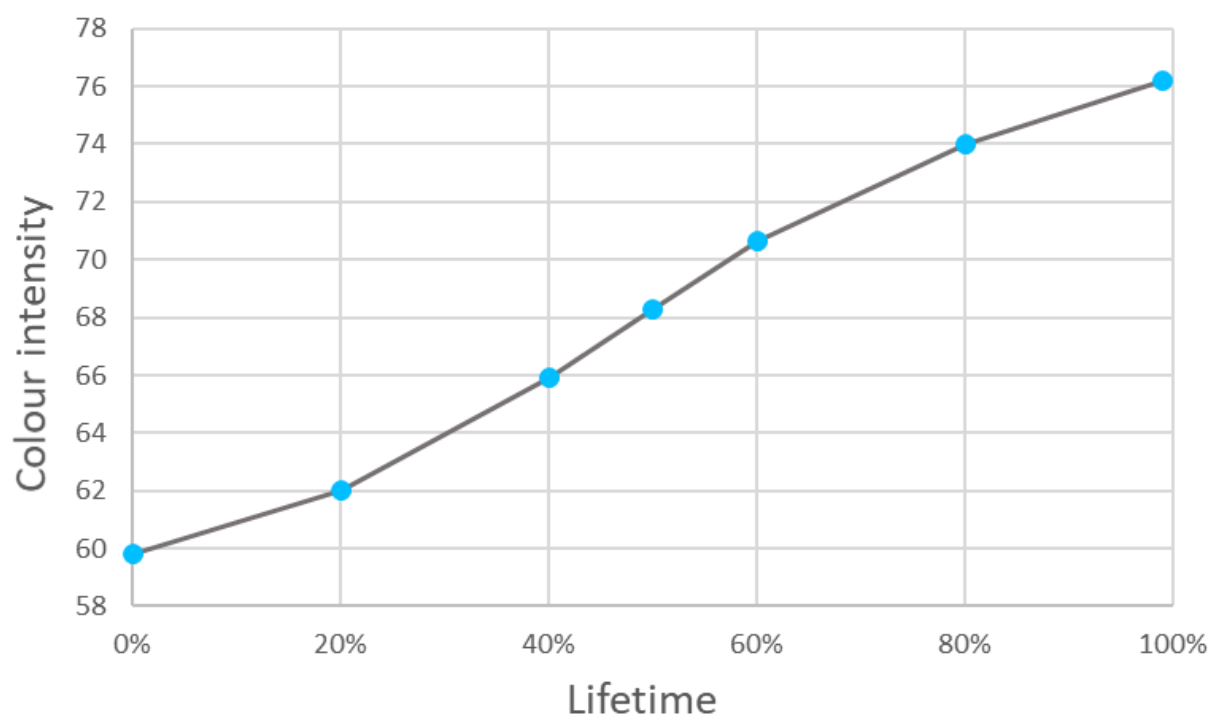

Figure 7:

Diagram of change of colour intensity

Another possibility, as an alternative to the diameter measurement, is the measurement of the visible area, Figure 8 . This would include not only the main body of the rope but also protruding fringes. In Figure 9 the corresponding diagram can be seen. At around 60\%, the line is rising steeper which again could be used as a point of discard.

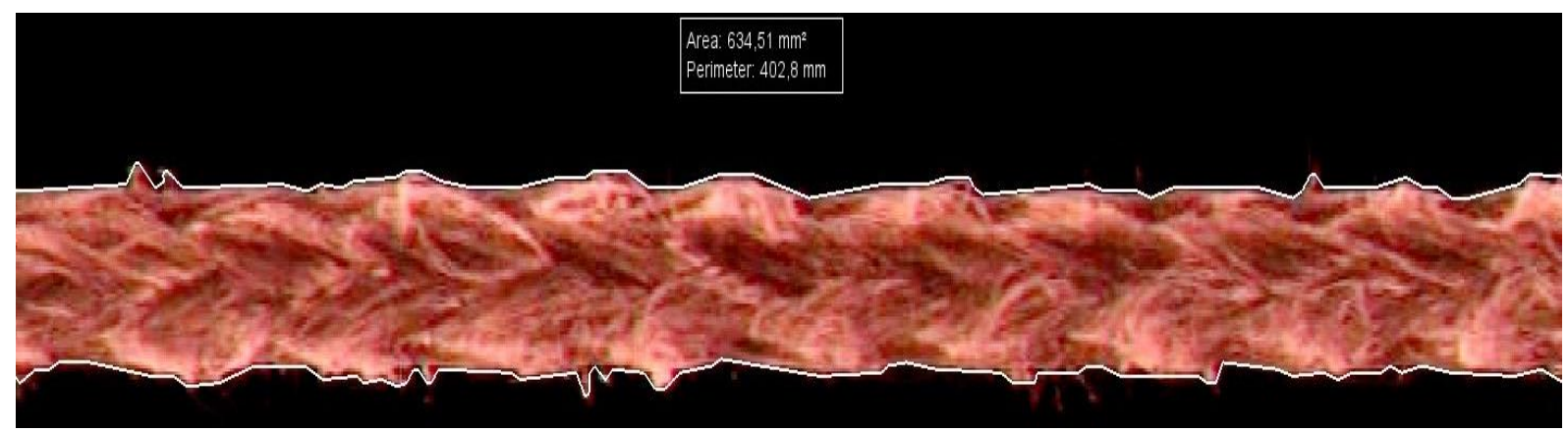

Figure 8: Measurement of visible area

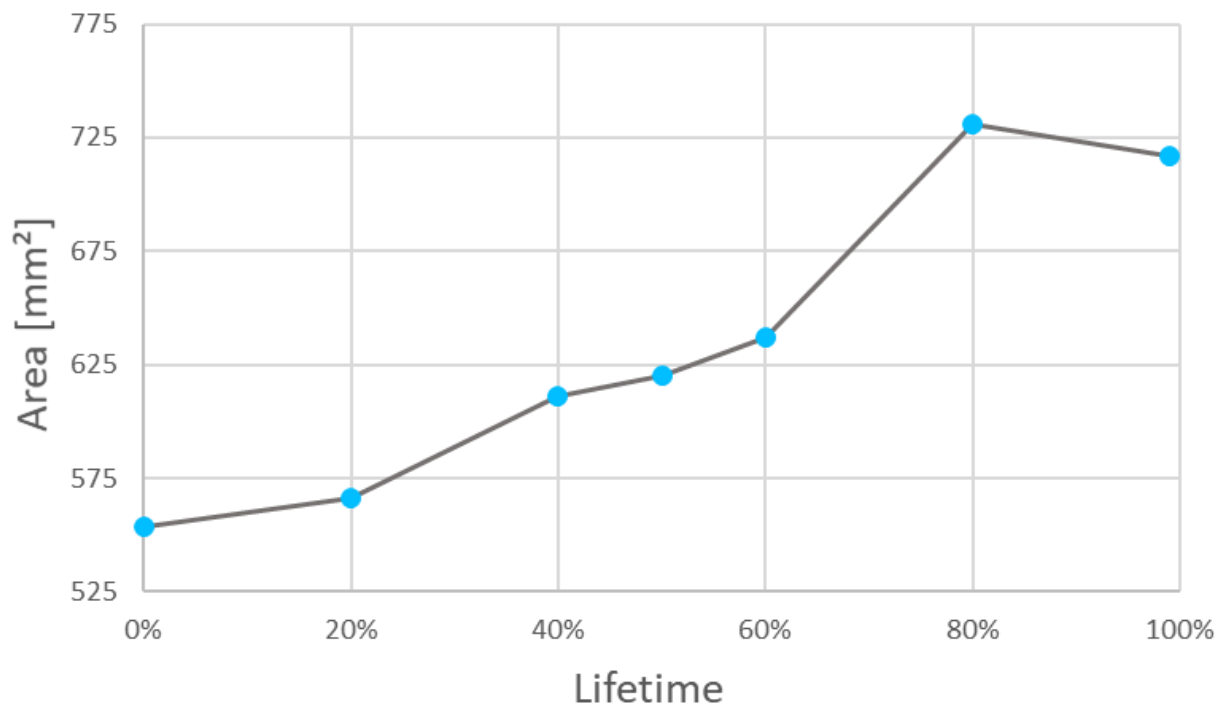

Figure 9: Diagram of visible area measurement 


\section{Conclusion}

High-modulus fibre ropes have the potential to be used in rope drives as an alternative to wire ropes. Compared to wire rope these types of fibre ropes offer a high lifetime, similar stretch and low self-weight. The disadvantages today are the rather high prices and the not sufficiently researched discard criteria.

At IFT, research is done in the field of high-modulus fibre ropes to establish reliable discard criteria. An additional working field is the development of an automated visual inspection system called Fibrespect that is based on the patented Winspect ${ }^{\circledR}$-system that will be further developed. With this combined approach, research on discard criteria and an inspection system, IFT wants to give the crane and rope drive manufacturers and operators the possibility to use high-modulus fibre ropes in a safe and reliable way. The possibilities for discard criteria of high modulus fibre ropes include the "standard" diameter and lay length measurements but also new approaches like the measurement of the colour intensity or the visible area.

\section{References}

[1] Feyrer, K.: Wire Ropes - Tension, Endurance, Reliability - 2nd Edition. Springer-Verlag, Heidelberg, 2015.

[2] FEM: FEM 5.024 - Guideline "Safe Use of High Performance Fibre Ropes in Mobile Crane Applications". Frankfurt, 2017.

[3] Samson Ropes: Samson Technical Bulletin - Inspection \& Retirement Pocket Guide. Ferndale, 2013.

[4] Teufelberger Fibre: soLite - Das hochfeste Faserseil für Krane. Product specification sheet Teufelberger. Wels, 2016

[5] Huntley, E.: Non-Destructive Test methods for high-performance synthetic rope. In: OIPEEC-Conference Proceedings 2015. Stuttgart, 2015.

[6] Cortland: Ultrasonic Non-destructive Structural Health Monitoring of Synthetic Ropes. IMCA Meeting 2015, 14. Mai 2015. Amsterdam, 2015.

[7] Harrach, A.: Die Weiterentwicklung des Winspect ${ }^{\circledR}$-Seilprüfgerätes vom Einsatz bei Seilbahnen bis zur Qualitätssicherung in der Produktion von Seilen. In: Stuttgarter Seiltage Proceedings 2018. Stuttgart, 2018.

[8] Wehking, K.-H.: Laufende Seile. Expert-Verlag, Renningen, 2018.

[9] ISO: ISO 4309 - 5th Edition - Cranes - Wire ropes - Care and maintenance, inspection and discard. Geneva, 2017.

[10] Novak, G.: Use of high-modulus fibre ropes in rope drives. In: OIPEEC-Conference Proceedings 2015. Stuttgart, 2015.

[11] Hansch, M.: Entwicklung einer bildgebundenen Methode zur Ablegereifeerkennung bei hochfesten Faserseilen. Proceedings Stuttgarter Seiltage 2018. Stuttgart, 2018.

[12] Schnepf, B.: Bestimmung der Ablegereife laufender hochmodularer Faserseile. Bachelor Thesis University of Stuttgart. Stuttgart, 2020. 